\title{
SIMULATIONS OF HURRICANE MATTHEW SURGE AND WAVES; COMPARISONS TO MEASUREMENTS
}

\author{
Christopher Bender, Taylor Engineering, Inc., cbender@taylorengineering.com \\ Ashley Kauppila, Taylor Engineering, Inc., akauppila@taylorengineering.com \\ Hunter Bredesen, Taylor Engineering, Inc., hbredesen@taylorengineering.com
}

\begin{abstract}
INTRODUCTION
Hurricane Matthew formed into a hurricane in the eastern Caribbean and rapidly intensified with peak intensity occurring in late September 2016 when the storm reached Saffir-Simpson Category 5 strength with 160 mph winds (Stewart, 2017). After leaving the Caribbean, Hurricane Matthew moved northward and remained close to the coasts of Florida, Georgia, South Carolina, and North Carolina and caused elevated water levels, large waves, and extensive coastal erosion.
\end{abstract}

\section{APPROACH}

As part of the United States (U.S.) Federal Emergency Management Agency (FEMA) effort to update coastal flooding estimates, FEMA Region IV (U.S. southeastern states) developed refined storm surge and wave models along the east coast of Florida and the Georgia and Carolina coasts (FEMA, 2013). As part of these studies, Taylor Engineering developed and executed the twodimensional hydrodynamic and wave model, SWAN+ADCIRC, necessary to develop new low frequency storm surge levels. To extend the FEMA Region IV studies, Taylor Engineering executed simulations of Hurricane Matthew with the Oceanweather Inc. two-dimensional wind and pressure fields ("best winds") to understand how well the recently completed FEMA models reproduce the Hurricane Matthew water levels and waves. Both the U.S. National Oceanographic and Atmospheric Administration (NOAA) and the U.S. Geological Survey (USGS) measured water level data at stations along Hurricane Matthew's track. NOAA also collected offshore wave data at stations near the U.S. southeast coastline.

Hurricane Matthew's track, which hugged the shoreline from central Florida to North Carolina, caused a large hurricane warning area and significant uncertainty in the storm surge estimates. Taylor Engineering completed simulations with the Hurricane Matthew track shifted shoreward and seaward to examine how sensitive the storm surge and waves were to the track path. These simulations provide useful information for potential future storms and can show how much Hurricane Matthew's surge could have changed with a landward or seaward shift.

\section{RESULTS}

The SWAN+ADCIRC simulations for Hurricane Matthew show good agreement with available measured water level and wave data. The simulated water levels show the SWAN+ADCIRC model can reproduce the timing and magnitude of the storm surge. For the offshore and coastal wave stations, the SWAN+ADCIRC model results show good agreement with the measured significant wave height, peak period, and mean wave direction in the lead-up to peak conditions and at peak conditions.
The SWAN+ADCIRC model results for the Hurricane Matthew shifted track simulations showed the sensitivity of the total water levels to the timing of the tides and the storm-induced water level changes. Shifts of the track parallel to the northeast Florida coast that moved the storm closer to shore only showed modest increases in the total water level. However, shifting the track to the northwest altered the timing of the storm's passage with the local tidal signal and resulted in large changes to the total water level along the northeast Florida and Georgia coastlines.

\section{SUMMARY}

Simulations of Hurricane Matthew with the SWAN+ADCIRC model and the FEMA Region IV model settings and model mesh show the model can reasonably reproduce measured coastal water level and wave conditions. The study and results should prove relevant to those conference attendees interested in coastal modeling and coastal processes analysis and management. Study results will also provide insights into how the recently developed FEMA models reproduce a storm that influenced the east coast from Florida to North Carolina.

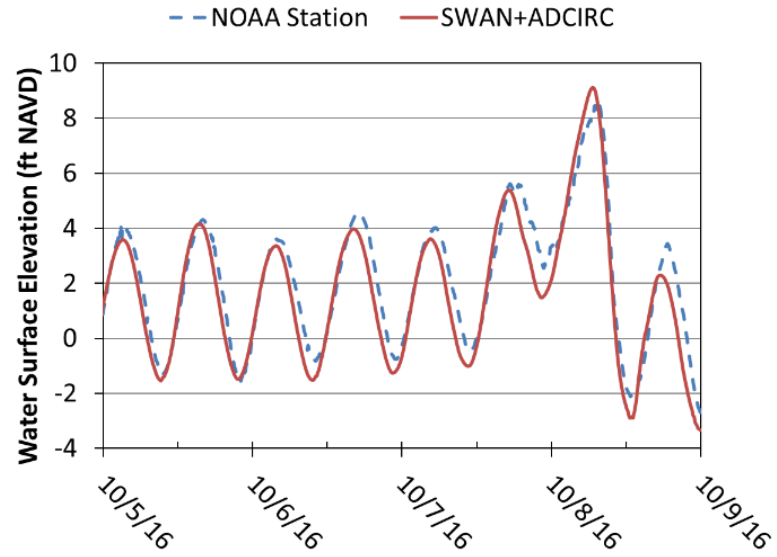

Figure 1 - Comparison of measured and SWAN+ADCIRC simulated water levels at NOAA's Fort Pulaski Station.

\section{REFERENCES}

Federal Emergency Management Agency (FEMA). 2013. Georgia and Northeast Florida Storm Surge Project Deliverable 2: Validation Report. Prepared for FEMA Region IV. BakerAECOM, LLC.

Stewart, S.R. 2017. National Hurricane Center Tropical Cyclone Report: Hurricane Matthew. AL14016. National Oceanographic and Atmospheric Administration (NOAA). 